\title{
A VIOLAÇÃO DOS DIREITOS TERRITORIAIS INDÍGENAS: PRÁTICAS COLONIAIS E CONTEMPORÂNEAS
}

\author{
THE VIOLATION OF INDIGENOUS TERRITORIAL RIGHTS: \\ COLONIAL AND CONTEMPORARY PRACTICES
}

\author{
Junia Fior Santos ${ }^{1}$
}

Resumo: As presentes considerações, pontuadas a partir de uma visão histórica, social e jurídica, são um chamado à discussão aos fatos históricos relacionados à violação e expropriação dos territórios indígenas consolidados de forma aparentemente legal. Por sua vez, procura-se analisar as nuances do processo interpretativo acerca do direito indígena à terra de origem. Neste contexto, muitos são os desafios na execução de direitos, considerando o atual cenário político, por um lado reflexo de conformações e deficiências de discernimento e, por outro, fomentador de usos contra-hegemônicos do direito, que teoricamente prioriza a defesa da emancipação social.

Palavras-chave: Direito Indígena; Legislação Territorial; Marco Temporal.

Abstract: These considerations, based on a historical, social and juridical vision are one called to the discussion of historic facts related with the violation and expropriation of consolidated indigenous territories in a legal way, apparently. It seeks to analysis the nuances of the interpretative process about indigenous right to their origin land. In this context, many are the challenges to execution of rights, considering the present political scenario, that is by one side reflex of conformations and discernment deficiency and, by other side, developer of counter-hegemonic uses of right, that theoretically prioritize the defense of the social emancipation.

Keywords: Indigenous Right; Territorial Legislation; Time Frame.

\section{INTRODUÇÃO}

$\mathrm{O}$ reconhecimento oficial dos direitos indígenas, ainda que por vezes com justificativa humanista, foi discutido em diversas circunstâncias ao longo da história de nosso país, inclusive com a ratificação de direitos no período colonial. Mas como

\footnotetext{
${ }^{1}$ Especialista em História e Cultura Indígena (UFMS). Mestranda em História Indígena pelo Programa de Pós-Graduação em História da Universidade Federal da Grande Dourados - MS (UFGD). Bolsista CAPES.
} 
A VIOLAÇÃO DOS DIREITOS TERRITORIAIS INDÍGENAS: PRÁTICAS COLONIAIS E CONTEMPORÂNEAS Junia Fior Santos

estará delineado no decorrer do presente trabalho, esses direitos não se efetivaram como teoricamente previsto.

O maior desafio enfrentado pelos povos indígenas na efetivação de seus direitos continua sendo a demarcação de suas terras de ocupação tradicional, que constitui a base da sobrevivência física, social, política e cultural dessas comunidades.

O presente trabalho objetiva demonstrar a fragilidade e ausência de efetivação dos direitos dos povos indígenas à demarcação de terras no Brasil, considerando as implicações tanto do âmbito judicial quanto social que fomentam a presente discrepância existente entre a legislação e sua aplicabilidade.

Para tanto, serão analisados acontecimentos concretos e emblemáticos da trajetória histórica de reconhecimento e violação dos direitos territoriais indígenas, como a tese do marco temporal que envolve esta temática, a fim de delinear as principais implicações sociais que possuem influência direta na insegurança jurídica vivenciada pelas comunidades indígenas em território nacional.

\section{A LEGISLAÇÃO TERRITORIAL BRASILEIRA}

Ao analisarmos a atual conjuntura de direitos indígenas no Brasil é preciso retornar ao contexto em que tal ordenação de caráter ocidental foi imposta aos povos indígenas. A legislação indigenista brasileira foi implementada por indivíduos que atacaram, saquearam, ocuparam e se autodenominaram descobridores e colonizadores. Esses invasores foram responsáveis por um genocídio desenfreado, motivado pela ganância e ambição. Para a exploração dos recursos naturais do Novo Mundo foram estabelecidos alguns projetos de colonização, que foram gradativamente sendo modificados ${ }^{2}$, o que moveu muitos debates acerca dos direitos territoriais, os quais não incluíam a participação dos povos indígenas.

A política indigenista foi norteada por um projeto colonial usurpador emitido pela Coroa portuguesa. Conforme nos ensina Perrone a respeito dos princípios da legislação indigenista do período colonial: "Contraditória, oscilante, hipócrita: são esses os adjetivos empregados, de forma unânime, para qualificar a legislação e a

\footnotetext{
${ }^{2}$ A mortandade que integrou o processo de colonização provocou "esse resultado espantoso de reduzir uma população que estava na casa dos milhões em 1500 aos parcos 200 mil índios que hoje habitam o Brasil”" (CUNHA, 1992, p. 12).
} 
A VIOLAÇÃO DOS DIREITOS TERRITORIAIS INDÍGENAS: PRÁTICAS COLONIAIS E CONTEMPORÂNEAS Junia Fior Santos

política da Coroa portuguesa em relação aos povos indígenas do Brasil colonial" (Perrone-Moisés, 1992, p. 115). Além de ser antagônica no tocante à determinação dessas leis, a sua aplicabilidade ficava restrita apenas ao campo do legislativo, não se efetivando em qualquer meio social.

A legislação portuguesa implantada na colônia brasileira reconhece desde o século XVI, os direitos das populações indígenas às terras que ocupavam. Nesse seguimento, Perrone menciona o trecho de um documento jurídico que expressa: "o gentio será o senhor de sua fazenda, asi como o he na serra" (Perrone-Moisés, 1992, p. 119). Tal afirmação demonstra que o reconhecimento do direito aos territórios indígenas era vigente, essas terras da serra se referem as terras de onde foram retirados por meio do projeto de "descimento" para a costa, ao se aproximarem dos portugueses os indígenas seriam aldeados em pequenas porções de terras administradas pelos missionários. Os povos indígenas que se deslocavam para essas fazendas, perderiam, portanto, legalmente, os direitos sobre as terras da serra.

As terras utilizadas para o aldeamento seriam cedidas apenas aos indígenas considerados aliados, ou seja, os que aceitassem a conversão à religião cristã. Aos indígenas que se negassem deslocarem-se para as aldeias, era declarada a "Guerra Justa" ${ }^{3}$, assim os que aceitassem o descimento receberiam terras em sesmaria, que eram terras devolutas e por isso poderiam ser cedidas para que a lei que previa o direito ao território fosse efetivada.

No que se refere ao propósito de equilibrar posições antagônicas, as leis e a política da Coroa portuguesa mostraram pouca preocupação com a questão jurídica colonial, privilegiando o aspecto político econômico.

Por conseguinte, no decurso da história dos povos indígenas do Brasil, é possível observar o emprego de diferentes meios de desrespeito e violências institucionalizadas, que se iniciaram com a depreciação da humanidade, passando pela tentativa de extermínio das culturas indígenas e, na contemporaneidade, pelo

\footnotetext{
${ }^{3}$ Conforme nos ensina Perrone (2017, p. 42), o termo "Guerra Justa" se refere a uma concepção ideológica que orienta as regras de conduta que delimita em quais situações a guerra é ou não uma prática aceitável. Desse modo, era empregada como um permissivo para a escravização dos indígenas que se encontrassem em conflito com os colonos.
} 
A VIOLAÇÃO DOS DIREITOS TERRITORIAIS INDÍGENAS: PRÁTICAS COLONIAIS E CONTEMPORÂNEAS Junia Fior Santos

limite ao exercício da cidadania e negação aos direitos básicos para sobrevivência das comunidades indígena.

Assim, para compreender o debate jurídico contemporâneo sobre os direitos dos povos indígenas, é necessário realizar um resgate histórico que contemple os mais importantes acontecimentos que visam o retrocesso de direitos às populações indígenas no itinerário da legislação brasileira.

O reconhecimento legal dos direitos indígenas perpassa três períodos históricos, sendo eles: colonial, imperial e republicano. Os três momentos apresentam muitas rupturas, porém muitas permanências, entre essas cabe destacar a predominância do tratamento colonizador, que considerou os povos indígenas efêmeros, em transição para a civilização, depois para a assimilação e por fim para o desaparecimento.

É somente no século XIX que as discussões acerca da "humanidade" dos índios ganham maior atenção, havendo muitos debates sobre quais as melhores medidas a se tomar para "civilizar" esses povos.

Assim como Von Martius, Francisco Adolpho de Varnhagen e Carl Friedrich Philipp, que não admitiam a humanidade dos índios e diligenciavam difundir julgamentos racistas e classistas, tivemos outros intelectuais como José Bonifácio de Andrada e Silva que contribuiu para o projeto do primeiro regime tutelar, que previa a mestiçagem como meio de incorporação dos índios à civilização. Embora o projeto de Bonifácio tenha tido boa aceitação, não foi incorporado à Constituição de 1824, que não proferiu nenhuma posição em relação aos povos indígenas. Mesmo assim, os investimentos para aumentar os territórios transitáveis e limitar o acesso à terra aos povos indígenas continuou se fortalecendo.

Em 1850 foi aprovada a Lei de Terras, que visava a organização das propriedades privadas no país, entre as determinações, essa lei reconheceu o direito indígena ao território, uma vez que esses seriam oriundos dessas terras, ou seja, os índios tiveram os direitos originários legalmente reconhecidos como designa a Lei $\mathrm{n}^{\circ}$ 601 , de 18 de setembro de 1850, Art. $12.4^{4}$

\footnotetext{
${ }^{4}$ BRASIL LEI 601 DE 18 DE SETEMBRO DE 1850. Disponível em: Gov.br/ccivil_03/Leis/L061-1850.htm. Acesso em: 20 dez. 2017.
} 
A VIOLAÇÃO DOS DIREITOS TERRITORIAIS INDÍGENAS: PRÁTICAS COLONIAIS E CONTEMPORÂNEAS Junia Fior Santos

Destarte, cabe atualmente indagar quando e por que essa interpretação foi modificada, corroborando para o esclarecimento do recente posicionamento do Supremo Tribunal Federal a respeito do não reconhecimento ao direito originário, portanto imemorial dos indígenas aos seus territórios. Decisão que é contraditória aos parâmetros historicamente usuais.

A legislação brasileira sempre reconheceu o direito indígena ao território que tradicionalmente ocupam, e não que estivessem ocupadas em 1988 como defende a nova (re) intepretação do texto constitucional. Fato que corrobora para a digressão dos direitos indígenas e o apagamento de sua natureza jurídica, sendo essa mais uma das estratégias utilizadas para o favorecimento de interesses econômicos. Conforme salienta Daniela Gomes:

No debate envolvendo o direito indígena à posse das terras tradicionalmente ocupadas, em contraponto ao direito à propriedade privada pelos agricultores, é possível perceber que, além de a teoria dos direitos fundamentais estar submersa no utilitarismo, também as decisões judiciais, em sua grande maioria, ao enaltecer a sobreposição do direito à propriedade privada, utilizando argumentos sob um viés puramente econômico da questão (produtividade), perpetuam um utilitarismo travestido (GOMES, 2017, p. 137).

Apesar da constituição de 1988 viabilizar a possibilidade de concretização do projeto de justiça de ordenação histórica, ao legitimar os direitos dos povos indígenas aos seus territórios de origem, essas garantias constitucionais têm sido desafiadas por interesses pessoais de grupos que se apoiam em um sistema judicial tendencialmente conservador e retrógrado.

Contudo, é inegável reconhecer que a constituição de 1988 representou um marco importante no tocante aos direitos indígenas, esclareceu, ampliou e especificou de forma sistemática os direitos originários dos povos indígenas às terras, estabelecendo uma nova dimensão para o preceito jurídico, que assim definiu:

Art. 231. São reconhecidos aos índios sua organização social, costumes, línguas, crenças e tradições, e os direitos originários sobre as terras que tradicionalmente ocupam, competindo à União demarcá-las, proteger e fazer respeitar todos os seus bens. 
A VIOLAÇÃO DOS DIREITOS TERRITORIAIS INDÍGENAS: PRÁTICAS COLONIAIS E CONTEMPORÂNEAS Junia Fior Santos

Assim sendo, a Constituição Federal de 1988 reconhece aos povos indígenas do Brasil o direito originário em relação às terras que tradicionalmente ocupam. Logo, a condição "originário" manifesta que o direito dos povos indígenas antecede ao próprio direito, sendo anterior a própria lei.

Desde o reconhecimento dos direitos indígenas, não se pode declarar que os progressos em sua execução sejam expressivos, pelo contrário, o Poder Judiciário, o qual exerce função determinante na efetivação desses direitos, tem sustentado um posicionamento fortemente conservador em relação à real aplicação das leis, levando os povos indígenas a recorrerem ás instâncias internacionais, como a Corte Interamericana de Direitos Humanos para atrair atenção para os problemas e urgências locais.

O processo de demarcação de terras indígenas, que se apresenta como uma das principais demandas desses povos, encontra grandes obstáculos e morosidade em sua efetivação, mesmo diante da edição do ato de disposições transitórias, cuja redação se moldou no artigo $67^{5}$ da constituição, que dispõe sob a conclusão de todo o processo de demarcação em 5 anos. Porém, por abnegação, grande parte das pretensões demarcatórias não foram reconhecidas pelos organismos competentes no prazo determinado, sendo tal tratativa desrespeitada tanto pelas políticas governamentais quanto pelo próprio poder judiciário.

Tal omissão teve um gritante impacto social na sociedade como um todo, especialmente sob as populações indígenas, tendo em vista que, hoje, um processo de demarcação pode durar até mesmo décadas.

A (re)interpretação que tem sido feita do atual texto constitucional, no que tange ao direito originário às terras indígenas e ao que este inclui, vem sendo motivo de preocupações em relação a definição e reformulação conceitual de direito imemorial e direito originário.

Conjuntamente se tem examinado a concepção de ocupação tradicional, considerando, ou não, o direito originário, especialmente relacionado a uma ocupação

\footnotetext{
5 “Art. 67 (ADCT) A União concluirá a demarcação das terras indígenas no prazo de cinco anos a partir da promulgação da Constituição".
} 
A VIOLAÇÃO DOS DIREITOS TERRITORIAIS INDÍGENAS: PRÁTICAS COLONIAIS E CONTEMPORÂNEAS Junia Fior Santos

apenas física, em oposição a ratificação jurisprudencial do direito originário, que reconhece historicamente a ocupação tradicional como não física.

Cumpre destacar que "não houve com a CF/88 a criação de novas áreas indígenas, mas sim o reconhecimento do direito indígena ao solo, enquanto direito originário, através da ocupação tradicional” (GOMES, 2017, p. 146). A prática demarcatória está em consonância com o artigo $231 \S 1^{\circ}$, que considera o caráter material e imaterial para o preenchimento dos critérios básicos de comprovação da perdurabilidade com a terra reivindicada. Critérios esses que devem ser rigorosamente avaliados por profissionais designados para o estudo de identificação e demarcação territorial, responsáveis por realizar o levantamento de informações acerca da relação material que os requerentes tem com a terra, assim são realizados estudos de natureza etno-histórica, cartográfica, sociológica, ambiental, jurídica e o levantamento fundiário que também abarca a relação imaterial, que reúne os aspectos cosmológicos, como relação espiritual e ancestral que estes indivíduos possuem com o território.

De tal forma, obrigados a afastar-se de seus territórios para que outros viessem a ocupá-los, os povos indígenas tiveram sérios transtornos em suas organizações sociais e físicas, que acarretou problemas em seu modo tradicional de vida. Como já mencionado, nos séculos anteriores, a transitoriedade ocasionada pelos processos de esbulho, como os "descimentos" provocaram deslocamentos para diversos espaços físicos, vários foram os fatores que dificultaram a reocupação desses locais sendo vedada a presença em terras de origem tradicional em 1988, pois haviam sido expulsos em virtude de conflitos possessórios.

Esses conflitos territoriais iniciados com o processo de colonização persistiram e perpassaram o marco demarcatório temporal da data de 1988, e continuam se sustentando até a contemporaneidade. Os povos indígenas não abandonaram seus territórios de origem, pois sempre houve tentativas de aproximação e lutas pela terra, mesmo após intensos conflitos.

A constituição de 1934 que ampliou as perspectivas de mudanças para grande parte dos brasileiros, foi a primeira a atribuir tratamento constitucional aos direitos dos 
A VIOLAÇÃO DOS DIREITOS TERRITORIAIS INDÍGENAS: PRÁTICAS COLONIAIS E CONTEMPORÂNEAS Junia Fior Santos

povos indígenas ${ }^{6}$, entre esses o direito à posse das terras que ocupavam, como expressa o Art. 129:

Será respeitada a posse de terras de silvícolas que nelas se achem permanentemente localizados, sendo-lhes, no entanto, vedado aliená-las.

Posteriormente, o texto constitucional de 1937, Art. 154, reafirma o decreto à terra:

Será respeitada aos silvícolas a posse das terras em que se achem localizados em caráter permanente, sendo-lhes, no entanto, vedado aliená-las.

Ambos os textos constitucionais, já revogados, são bastante claros ao determinar que as terras indígenas são aquelas que os indígenas ocupam "permanentemente", ou seja, em caráter perdurável.

É atribuída a União, mediante sua função executiva, a incumbência de delimitar essas terras, seguindo as regras do procedimento administrativo demarcatório para definir a legitimidade da demanda territorial. Corroborando com esse entendimento, a Constituição Federal de 1988 catalogou terras indígenas no rol de bens da União, ainda, em sua natureza jurídica reconheceu aos povos indígenas o direito originário às essas terras tradicionalmente ocupadas, declarando-as constituintes do patrimônio indígena ${ }^{7}$.

É importante ressaltar que o governo passou a adotar medidas que fomentaram a inaplicabilidade do texto constitucional por meio de artimanhas legislativas, como por exemplo tornar devolutas as terras indígenas, repassando-as e loteando-as para proprietários particulares e empresas, caracterizando tal prática como fraudulenta e elegível a ser adotada por inúmeros estados.

Assim, ao invés dos Estados viabilizarem o respeito às terras indígenas, e a consolidação destas, viabilizaram medidas e forças para expulsar os povos indígenas gradativamente das terras tradicionalmente ocupadas. Essas práticas têm se inovado,

\footnotetext{
${ }^{6}$ Antes de constar na Constituição Brasileira de 1934, o reconhecimento do direito originário já tinha sido afirmado pela Coroa Portuguesa em Alvarás (Perrone-Moisés, 1992).

${ }^{7}$ Em concordância com o artigo 39 do Estatuto do Índio.
} 
A VIOLAÇÃO DOS DIREITOS TERRITORIAIS INDÍGENAS: PRÁTICAS COLONIAIS E CONTEMPORÂNEAS Junia Fior Santos

como se nota na mais recente proposta da tese do marco temporal, que representa mais uma das artimanhas legislativas para driblar os ditames constitucionais.

TESE DO MARCO TEMPORAL - BREVES CONSIDERAÇÕES ACERCA DA TERRA INDÍGENA RAPOSA SERRA DO SOL

No julgamento da constitucionalidade e da legalidade da demarcação da Terra Indígena Raposa Serra do Sol (Petição $n^{\circ}$ 3.388), foi apresentado um dos mais recentes marcos de reavaliação e modificação na política indigenista brasileira, tornando questionável a interpretação do texto constitucional de 1988.

A demanda objetivava impugnar a Portaria n. 534/2005 do Ministro da Justiça homologada pelo Presidente da República, em 15 de abril de 2005, que promoveu a demarcação da terra indígena Raposa Serra do Sol no estado de Roraima ${ }^{8}$. A portaria fora fortemente questionada por via judicial, especialmente pelos produtores rurais da região (arrozeiros), e o Governo do estado de Roraima.

O Superior Tribunal Federal seguiu o parecer do relator Ministro Carlos Ayres Britto, reconhecendo a legalidade do processo administrativo da demarcação, afastando assim qualquer argumento sob a violação à soberania nacional a segurança territorial, tendo em vista a proximidade das terras demarcadas com a fronteira da Guiana francesa e da Venezuela, sendo esta uma das maiores preocupações das forças armadas do Brasil. Em síntese o julgado demarcatório não restringiu a demarcação à pequenas ilhas como requisitado pelo estado e pelos proprietários rurais, e estabeleceu que tal decisão não violaria o pacto federativo.

Os ministros do Supremo Tribunal Federal (STF) estabeleceram 19 condicionantes que, em suma, poderão limitar o controle das comunidades indígenas sob as terras demarcadas. Consolidando a decisão a partir do "Conteúdo Positivo do ato de Demarcação das Terras Indígenas"9. Concomitantemente reforçou o reconhecimento de uma discussão levantada em contextos anteriores a respeito de

\footnotetext{
8 Brasil. Supremo Tribunal Federal. Julgamento petição 3.388 petição 3.388/ RO. Disponível em: http://stf.jus.br/portal/jurisprudencia/visualizarEmenta.asp?s1=000168444\&base=baseAcordaos. Acesso em: 06 jan. 2018.

${ }^{9}$ Brasil. Supremo Tribunal Federal. Supremo tribunal Federal. Dispõe 19 condições para demarcação de terras indígena. Publicação $19 . \quad$ Março de 2009 Disponível http://www.stf.jus.br/portal/cms/verNoticiaDetalhe.asp?idConteudo=105036. Acesso em: 06 jan. 2018.
} 
A VIOLAÇÃO DOS DIREITOS TERRITORIAIS INDÍGENAS: PRÁTICAS COLONIAIS E CONTEMPORÂNEAS Junia Fior Santos

uma rigorosa distinção entre terra indígena e território, propondo uma nova interpretação acerca desses conceitos, declarando precisamente que a CF/88 não abrange a expressão "território indígena".

A antropóloga Dominique Gallois, explica-nos a diferenciação básica entre terra e território:

[...] a diferença entre "terra" e "território" remete a distintas perspectivas e atores envolvidos no processo de reconhecimento e demarcação de uma Terra Indígena. A noção de "Terra indígena" diz respeito ao processo político-jurídico conduzido sob a égide do Estado, enquanto a de "território" remete à construção e à vivência, culturalmente variável, da relação entre uma sociedade específica e sua base territorial (Gallois, 2004, p. 39).

A nova interpretação do STF ao Art. 231 não inclui o espaço em que os povos indígenas podem construir seus aspectos sociais, simbólicos, culturais e políticos, particulares a cada identidade étnica, pois esta noção de espaço físico não condiz com a categorização singular que os não indígenas aderem a "terra". Nesse sentido, a terra não abarca a noção de territorialidade, que por sua vez é mais ampla e inclui o direito originário.

Este critério, no que tange ao marco temporal da ocupação, causa espanto pois constrange o direito à terra indígena, além da interpretação gramatical como é perfeitamente visível pela observação do próprio texto constitucional.

O texto da carta magna é claro em não determinar um lapso temporal de ocupação, apesar de exigir o caráter permanente da ocupação pelas comunidades indígenas, pois tais exigências vão de encontro justamente ao marco de tradicionalidade; além da possibilidade de esbulho renitente, que é uma situação de fato caracterizada pelo efetivo conflito possessório entre os proprietários e a comunidade indígena, que se iniciou no passado e persistiu até o marco demarcatório temporal da data da promulgação da Constituição da República de 1988, materializado por circunstâncias de fato ou por controvérsia possessória judicializada.

A decisão em cerne apresenta uma grande falha, sendo esta mantida de forma proposital, visto que o direito da comunidade indígena à terra por meio do marco temporal não guarda correlação com a situação sócio-jurídica vivenciada pela 
A VIOLAÇÃO DOS DIREITOS TERRITORIAIS INDÍGENAS: PRÁTICAS COLONIAIS E CONTEMPORÂNEAS Junia Fior Santos

comunidade indígena, bem como as dificuldades e problemas enfrentados que vão desde a violência até mesmo legislações retrógradas, restringindo assim o número de demandas e pleitos viáveis a demarcação.

Deste modo é visível que a presente decisão quanto ao marco temporal é repleta de falhas, frente ao estabelecimento arbitrário de um referido lapso temporal para se chegar a uma resposta rasa e repleta de vícios, que contesta toda a história dos povos indígenas no Brasil. Neste sentido, Bruno Pegorari esclarece:

(...) A verdade é que o estabelecimento arbitrário da referida data carrega o vício da anti historicidade, ignorando o passado indigenista brasileiro e o caráter originário de seus direitos, assim como o histórico compartilhado das graves violações dos direitos humanos desses povos por parte de particulares e do próprio Estado. Por fim a preocupação de "jogar uma pá de cal" para pôr fim às discussões, sobre a matéria, nas próprias palavras do relator, nos pareceu mais uma afobação em resolver o já prologado debate que de fato um anseio em dar-lhe uma mais apropriada solução. É verdade que esta decisão produziu efeito restrito às partes processuais daquele caso concreto. Todavia o caso foi apenas um impulso inicial da tese jurídica do marco temporal da ocupação (PEGORARI, 2017, p. 249).

Outro fator preocupante é que a Advocacia Geral da União registrou o parecer 001/2017, ratificado pelo presidente Michel Temer em 19 Julho de 2017, requisitando que todos os processos demarcatórios envolvendo terras indígenas obedeçam as 19 condicionantes registradas no julgamento da Petição 3.388/RR da terra indígena Raposa Serra do Sol, limitando assim as matérias e condições ali estabelecidas, estando as demandas adstritas ao que dispõe as 19 condicionantes estabelecidas no julgado da petição n. 3.388- 2009, inclusive a submissão de todas as novas decisões que venham a volver a presente matéria a todos os marcos ali estabelecidos, até mesmo ao famigerado marco temporal. Como exposto a seguir:

A respeito deste parecer o excelentíssimo senhor presidente da república exarou o seguinte despacho. "Aprovo. Em 17-VII-2017 Parecer N. 001/2017/GAB/CGU/AGU Processo: 00400.002203/2016-01 Interessado: Casa Civil Da Presidência Da República. I. O Supremo Tribunal Federal, no acórdão proferido no julgamento da PET 3.388/PR, fixou as "salvaguardas institucionais às terras indígenas", as quais constituem normas decorrentes da interpretação da Constituição 


\section{HISTÓRIA \\ A VIOLAÇÃO DOS DIREITOS TERRITORIAIS INDÍGENAS: PRÁTICAS COLONIAIS E CONTEMPORÂNEAS Junia Fior Santos \\ e, portanto, devem ser seguidas em todos os processos de demarcação de terras indígenas. II. A Administração Pública Federal, direta e indireta, deve observar, respeitar e dar efetivo cumprimento, em todos os processos de demarcação de terras indígenas, às condições fixadas na decisão do Supremo Tribunal Federal na PET 3.388/PR, em consonância com o que também esclarecido e definido pelo Tribunal no acórdão proferido no julgamento dos Embargos de Declaração (PET-ED $3.388 / \mathrm{PR})^{10}$.}

O marco temporal é uma tese do campo jurídico que ultrapassa o campo social, pois alimenta a violência contra o povos indígenas ao tornar digna e legítima posses precárias, tendo em vista esbulhos, expulsões e até mesmo mortes, coroadas por meio de reiteradas jurisprudências tanto em primeira quanto em segunda instância, e que viabilizam a consolidação da aplicação generalizada e irrestrita da tese do marco temporal em todas as demandas que envolvam demarcação de terras indígenas, denegando, assim, o direito desses povos sob as terras que fazem jus.

Determinar as demarcações de acordo com a presença dos indígenas nas terras em data certa é medida atroz e injusta, pois apaga e nega toda violência fomentada pelo Estado durante o processo colonial, visando trucidar direitos territoriais durante a abertura e consequente expansão de frentes colonizadoras, quanto fora alimentada pelos governos seguintes. A respeito das contestações feitas à legislação colonial acerca do direito originário, Cunha esclarece com muita propriedade que: "O título dos índios sobre suas terras é um título originário, que decorre do simples fato de serem índios: esse título indigenato, o mais fundamental de todos, não exige legitimação" (Cunha, 1992, p. 141-142). Assim como o processo de reconhecimento colonial fora claro com relação ao título originário, a CF/88 também é, contudo, as novas interpretações carregam as mesmas incongruências.

Tal proposta adentrou o julgamento dos embargos de declaração da Petição $\mathrm{n}^{\circ}$ 3.388, onde o Ministro do Supremo Tribunal Federal Luís Roberto Barroso frisou que: "A decisão proferida em ação popular é desprovida de força vinculante, em sentido

\footnotetext{
10 BRASIL. Advocacia Geral da União (AGU). Parecer 001/2017. Publicada 19/07/2017. Disponíveis em: http://www.agu.gov.br/page/atos/detalhe/idato/1552758. Acesso em 06 jan. 2018.
} 


\section{HISTÓRIA}

A VIOLAÇÃO DOS DIREITOS TERRITORIAIS INDÍGENAS: PRÁTICAS COLONIAIS E CONTEMPORÂNEAS Junia Fior Santos

técnico. Nesses termos, os fundamentos adotados pela Corte não se estendem, de forma automática, a outros processos em que se discuta matéria similar" ${ }^{\text {"11. }}$.

A presente decisão para obedecer a natureza que possui, pode ao máximo alçar a escala de efeito sobre as demais como precedente. Neste sentido, vale ressaltar a colocação posta pela atual presidente do Supremo Tribunal Federal, Ministra Cármen Lúcia, que explica: "O precedente serve, no sistema brasileiro, apenas como elemento judicial, orientador, inicialmente, para a solução dos casos postos a exame. É ponto de partida, não ponto de chegada" (Reclamação $\mathrm{n}^{\circ}$ $4.708 / \mathrm{GO})^{12}$.

A decisão judicial expõe a falta de segurança jurídica em relação aos direitos reconhecidos pelo Supremo, retrocedendo e dificultando em demasia o direito indígena ao reconhecimento de seus territórios.

Ademais, quanto ao poder judiciário, para além dos problemas que reportam ao ativismo judicial obsoleto, outro fator evidencia-se igualmente importante: a insistente valorização do direito individual à propriedade privada em detrimento do direito coletivo do uso da terra pelos povos indígenas, prezando a lógica da globalização hegemônica.

Sem dúvida alguma, os povos indígenas no decorrer dos últimos 517 anos, experimentaram várias formas de enfrentamento e resistência contra as intempéries ocasionadas a partir do contato com o não indígena. Nesse percurso de relações hostis, foram obtidas muitas conquistas, em especial no que se refere às leis que lhes reconhecem o direito às terras tradicionais, especialmente na Constituição de 1988. Contudo, as leis não tem sido o suficiente para a efetivação de tais direitos na medida que estes são constantemente violados.

Ademais, as demandas atuais não são constituídas exclusivamente por conflitos entre comunidades indígenas e latifundiários, essa é apenas uma faceta da problemática territorial, tal situação é mais abrangente, pois decorre primeiramente da

\footnotetext{
${ }^{11}$ BRASIL. Supremo Tribunal Federal. Embargos de Declaração da Petição 3.388. voto do Relator: Roberto Barrozo. Data da julgamento $2013 . \quad$ Disponível: http://redir.stf.jus.br/paginadorpub/paginador.jsp?docTP=TP\&docID=5214423 Acesso: 08 de jan. 2018

12 BRASIL. Supremo Tribunal Federal. Agravo Regimental na reclamação n. 4.708. data julgamento 2011 voto do Relator :Carmem Lúcia . Data da julgamento 2013 Disponivel: http://redir.stf.jus.br/paginadorpub/paginador.jsp?docTP=AC\&docID=622759. Acesso 08 jan. 2018
} 


\section{HISTÓRIA}

A VIOLAÇÃO DOS DIREITOS TERRITORIAIS INDÍGENAS: PRÁTICAS COLONIAIS E CONTEMPORÂNEAS Junia Fior Santos

omissão do poder público e da aplicação de políticas públicas que não atendem ao direito territorial, resguardado pela Constituição Federal de 1988.

Como se pode inferir, é difícil legitimar a efetivação dos direitos dos povos indígenas, embora exista uma Constituição Federal que, teoricamente, os ampara. Nota-se que a legislação, no que diz respeito a esses direitos, mesmo atingindo alguns progressos, mantém-se retrógrada quanto a sua execução. Isso porque, no tocante dessas garantias, ainda prevalecem e intervêm interesses alheios às demandas indígenas. Assim como no plano jurídico, como também na prática, não há como desconsiderar o cenário sócio-histórico marcado por arbitrariedades, e ilegalidades, nos processos de demarcação territorial.

\section{CONSIDERAÇÕES FINAIS}

Ao longo da história os povos indígenas obtiveram por meio de reivindicações certos direitos prescritos no ornamento jurídico colonial, imperial e republicano. Contudo, há um grande distanciamento entre o projeto político expresso nas leis e sua real efetivação.

A relação de colonialismo interno que se mostra presente na contemporaneidade é preocupante, tal postura impossibilita o acesso a direitos básicos dos povos indígenas que permanecem à mercê de uma administração pública que mostra falhas em sua real efetivação, inserindo os povos indígenas em um sistema codificado de atribuições que se rotula eficiente e justo na aplicação de políticas públicas, ao menos no planejamento teórico das ações.

A atenção dada pelo judiciário brasileiro aos direitos indígenas em especial ao direito à terra, vem se recopilando progressivamente, resultando, hoje, na abertura para debates que visam o retrocesso nos processos demarcatórios.

Os povos indígenas possuem pouca representatividade política, e seus direitos até mesmo os constitucionalizados quase não são efetivados, principalmente quando o órgão que possui função precípua de resguardar o que dispõe a Constituição Federal se omite, conclamando assim massificações de ações que utilizam impropriamente da tese do marco temporal para solucionar, indevidamente, demandas judiciais que envolvam a matéria. 


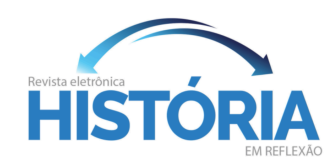

A VIOLAÇÃO DOS DIREITOS TERRITORIAIS INDÍGENAS: PRÁTICAS COLONIAIS E CONTEMPORÂNEAS Junia Fior Santos

Mesmo assim, a luta dos povos indígenas pela execução das leis que garantem as demarcações dos territórios de origem é algo incessante. Apesar do descaso da justiça brasileira, diversas comunidades têm se organizado em um movimento cada vez mais articulado e contam ainda com o apoio de órgãos indigenistas e interessados pela causa que acompanham de forma direta ou indiretamente esses impasses.

Assim como as "guerras justas" que foram apoiadas juridicamente pela Coroa Portuguesa, a qual se mantinha omissa diante do desrespeito e massacre aos povos indígenas, esses novos argumentos e ressalvas que ameaçam retroceder 0 reconhecimento de direitos desses povos faz ressurgir o contexto de novas guerras, novamente legitimadas com aval do Estado.

\section{REFERÊNCIAS BIBLIOGRÁFICAS}

BRASIL. Advocacia Geral da União (AGU). Parecer 001/2017. Publicada 19/07/2017. Disponíveis em: http://www.agu.gov.br/page/atos/detalhe/idato/1552758. Acesso em 06 jan. 2018.

Agravo Regimental na reclamação n. 4.708. data julgamento 2011 voto do Relator: Carmem Lúcia . Data da julgamento 2013 Disponivel: http://redir.stf.jus.br/paginadorpub/paginador.jsp?docTP=AC\&doclD=622759. Acesso 08 jan. 2018.

Constituição da República Federativa do Brasil de 1988. Disponível em: http://www.planalto.gov.br/ccivil_03/Constituicao/Constituicao.htm. Acesso em 04 jan. 2018.

Estatuto do Indio. 1973. Disponível em: http://www.planalto.gov.br/civil_03/leis/L6001.htm. Acesso em: 17 dez. 2017.

LEI 601 DE 18 DE SETEMBRO DE 1850. Disponível em: Gov.br/ccivil_03/Leis/L061-1850.htm. acesso em : 20 nov. 2017.

Supremo Tribunal Federal. Julgamento petição 3.388/ RO. Disponívelem:http://stf.jus.br/portal/jurisprudencia/visualizarEmenta.asp?s1=0001684 44\&base=baseAcordaos. Acesso em: 08 jan. 2018.

BRASIL. Supremo Tribunal Federal. Supremo tribunal Federal. Dispõe 19 condições para demarcação de terras indígena. Publicação 19. Março de 2009 Disponível

http://www.stf.jus.br/portal/cms/verNoticiaDetalhe.asp?idConteudo=105036. Acesso em: 12 jan. 2018. 


\section{HISTÓRIA}

A VIOLAÇÃO DOS DIREITOS TERRITORIAIS INDÍGENAS: PRÁTICAS COLONIAIS E CONTEMPORÂNEAS Junia Fior Santos

BRASIL. Supremo Tribunal Federal. Embargos de Declaração da Petição 3.388. voto do Relator: Roberto Barrozo. Data da julgamento 2013. Disponivel: http://redir.stf.jus.br/paginadorpub/paginador.jsp?docTP=TP\&doclD=5214423 Acesso: 12 de jan. 2018.

CUNHA, Manuela Carneiro da. (Org.). História dos Índios no Brasil. São Paulo: Cia das Letras, 1992. p. 9-26.

Política Indigenista no século XIX. In. CUNHA, Manuela Carneiro da. (Org). História dos Indios no Brasil. São Paulo: Cia das Letras, 1992, p. 134-155.

GALLOIS, Dominique. Terras? Territórios? Territorialidades? In: RICARDO, Fany (org.). Terras Indígenas \& Unidades de Conservação da natureza: o desafio das sobreposições. São Paulo: Instituto Socioambiental, 2004.

GOMES, Daniela. O direito Indígena ao Solo: limites e impossibilidades. 1. Ed. Rio de Janeiro: Lumen Juris, 2017.

OLIVEIRA, Roberto Cardoso de. 0 trabalho do antropólogo. $2^{\circ}$ Ed. São Paulo: UNESP, 2016.

PEGORARI, Bruno. A tese do "marco temporal da ocupação" como interpretação restritiva do direito à terra dos povos indígenas no Brasil: um olhar sob a perspectiva da Corte Interamericana do Direitos Humanos. ARACE - Direitos Humanos em Revista. Ano 4, número 5, fevereiro 2017.

PERRONE-MOISÉS, Beatriz. Índios livres e índios escravos: os princípios da legislação indigenista do período colonial (séculos XVI a XVIII). In. CUNHA, Manuela Carneiro da. (Org.). História dos Índios no Brasil. São Paulo: Cia das Letras, 1992. p. 115-132.

Artigo recebido em 04/09/2018 Artigo aceito em 05/01/2019 